\title{
Quality Improvement in Palliative Care Services and Networks: Preliminary Results of a Benchmarking Process in Catalonia, Spain
}

\author{
Xavier Gómez-Batiste, M.D., Ph.D., Carmen Caja, R.N., ${ }^{2}$ Jose Espinosa, M.D., ${ }^{1}$ Ingrid Bullich, R.N., ${ }^{2}$ \\ Josep Porta-Sales, M.D., Ph.D., ${ }^{3}$ Carme Sala, M.D., ${ }^{4}$ Esther Limón, M.D., Ph.D., ${ }^{5}$ Jordi Trelis, M.D., \\ Antonio Pascual, M.D., Ph.D., ${ }^{7}$ M. Luisa Puente, M.D., ${ }^{8}$ on behalf of the Working Group \\ of the Standing Advisory Committee for Palliative Care
}

\begin{abstract}
Background: A wide range of palliative care services has been implemented in Catalonia over the past 20 years. Quantitative and qualitative differences in the organization of palliative care services between districts and settings can result in wide variability in the quality of these services, and their accessibility.

Methods: We implemented a benchmark methodology to compare dimensions of care and organization, to identify aspects requiring improvement, and to establish indicators to measure progress. The overall aim was to generate a consensus document for submission to the Department of Health (DoH) of the Government of Catalonia.

Results: A Steering Committee convoked a meeting in Barcelona (Catalonia, Spain) and representatives $(n=114)$ of all the 37 districts within our health care remit (rural, urban, intermediate, and metropolitan) and settings of the health care system (hospitals, social health centers, community, and nursing homes) attended and took part in plenary sessions and workshops to define areas that, in their experience, were considered weak. Twenty-one consensus recommendations achieving high levels of consensus were generated for submission to the DoH. These included the formal definition of the model of care and organization of palliative care services at all levels in the region, the implementation of measures for improvement in different settings and scenarios, systems for continuous care, and facilities for the continuing training of health care personnel. These proposals have since been implemented in a trial region and, depending on the outcomes, will be applied throughout our health service.

Conclusion: We conclude that benchmark methodology is valuable in acquiring data for use in improving palliative care organization for patients' benefit.
\end{abstract}

\section{Introduction}

A WIDE RANGE of palliative care services have been implemented over the past 20 years in Catalonia, Spain. Quantitative outcomes such as the number of services, coverage estimates, and data on the use of resources are currently available. ${ }^{1}$ Studies on effectiveness of services ${ }^{2}$ and efficiency ${ }^{3,4}$ have also been described.

The organization of palliative care can be described on different levels ${ }^{5}$ from the basic model of care and intervention ${ }^{6}$

\footnotetext{
${ }^{1}$ WHO Collaborating Center for Palliative Care Public Health Programs. Catalan Institute of Oncology, Department of Health, Barcelona, Spain.

${ }^{2}$ Pla Director Sociosanitari, Department of Health, Government of Catalonia, Spain.

${ }^{3}$ Palliative Care Service, Catalan Institute of Oncology, Barcelona, Spain.

${ }^{4}$ Catalan Society for Palliative Care, Spain.

${ }^{5}$ Palliative Care Working Group, Catalan Society of Family Physicians, Spain.

${ }^{6}$ SECPAL (Spanish Society for Palliative Care), Spain.

${ }^{7}$ National Strategy for Palliative Care, Agency for Quality, Ministry of Health and Social Policies, Madrid, Spain.

${ }^{8}$ Department of Health, Autonomous Government of Catalonia, Spain.

Accepted May 12, 2010.
} 


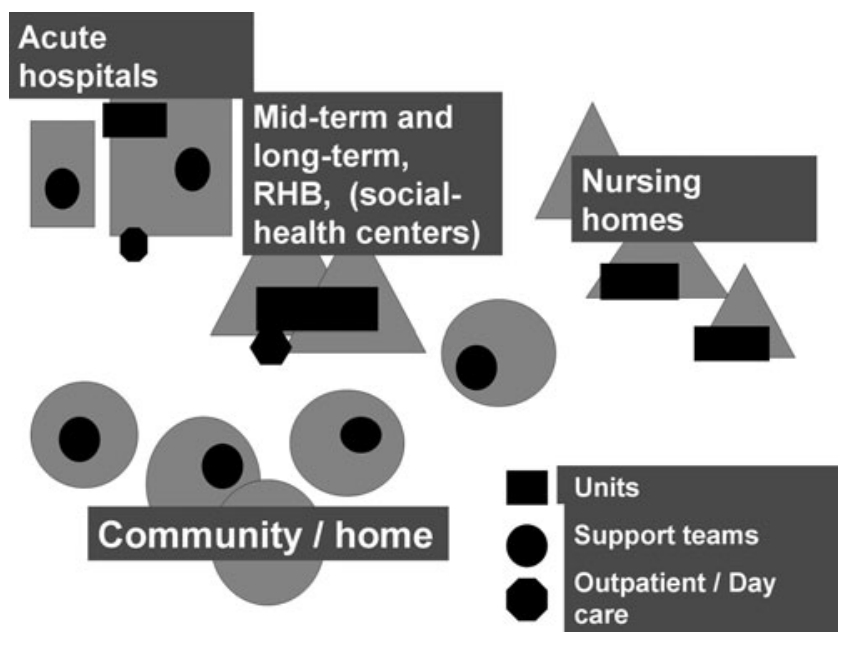

FIG. 1. Types and settings of palliative care services in Catalonia, Spain.

to the organization of multidisciplinary teams and different levels of specialist services. ${ }^{7}$

Identifying similar demographic scenarios (using mainly population and/or geographic criteria) and similar settings (of health care resources in which palliative care services are inserted [Fig. 1], e.g., hospitals, nursing homes, social health centers, community primary care, etc.) and describing the models of palliative care organizations in these scenarios and settings could be a useful way of comparing models, of planning and implementing services, and of identifying specific organizational indicators of standards of palliative care. ${ }^{5-13}$

There are 7 health care regions and 37 health care sectors in Catalonia. ${ }^{14}$ In 2008, there were 14,525 acute beds in 65 hospitals. The social health network includes 1921 convalescence/ rehabilitation beds, 679 palliative care beds, and 5916 longterm-care beds, more than 50,000 nursing home beds, and an extensive network of 359 public primary care centers. ${ }^{15,16}$

Currently, in 2009, the palliative care network ${ }^{17}$ encompasses a total of 236 specialist services (Table 1). Health care, including palliative care, in Catalonia (as in the rest of Spain) is universally available to all citizens free-of-charge at the point of access.

Overall, accessibility and coverage for patients with cancer is high, but two qualitative evaluations ${ }^{18,19}$ have shown some weak points and areas requiring improvement. Among other issues, one of the elements identified as needing improvement has been the variability in the organizational models of health care provision among districts; a factor that could cause nonequitable distribution of resources, unequal patterns of coverage or access, and differences in the quality of services provided.

Benchmarking has been defined as "the search for best practice that leads to superior performance. ${ }^{20}$ We extend this description to: the systematic cooperative process of identifying relevant dimensions of care and organization in similar services or settings; of defining parameters of excellence; of systematically comparing these elements to identify the deficiencies as well as the most developed areas in each element; of implementing individual and joint measures of improvement; and, finally, of establishing indicators to measure progress with the overall aim of improving the quality of care.
Table 1. Specialist Palliative Care Services in Catalonia ${ }^{19}$

Service type

Number

Home care support teams

74

Hospital support teams

38

Units

Outpatients clinics

Other services (psychosocial, others)

Other nonclinical services

(planning, training, research,

WHO Collaborating Center,

The QUALY Observatory)

Total specialist resources

The initial key issues in the benchmark processes (Table 2) are: to select the services, settings, and scenarios, and the dimensions for comparisons; to identify and to propose indicators and parameters for measurement; to propose and develop measures for implementation; and to measure the outcomes such as changes in quality. Selection of appropriate indicators is crucial in comparing and measuring changes. ${ }^{21}$

Benchmark evaluation has been applied extensively in health care provision. ${ }^{22,23}$ Different methodologies ${ }^{24}$ have been applied to settings, or specialties, such as nursing homes, ${ }^{25}$ end-stage renal disease ${ }^{26}$ cancer care centers, ${ }^{27}$ and in geriatric medicine. ${ }^{28} \mathrm{~A}$ benchmark process can also be used to improve quality of population- or province-based demographic scenarios. ${ }^{29}$ There are benchmarking studies comparing health care systems between countries and provinces, either with global dimensions ${ }^{30}$ or with specific end-of-life parameters. Administrative databases have been used as sources of quality indicators. ${ }^{31}$

Also, there are more specific applications for palliative care. ${ }^{32}$ These include the development of measuring tools or parameters, $^{33}$ the application of clinical tools, ${ }^{34,35}$ or the comparison of models of palliative care services ${ }^{13}$ such as academic hospitals for the care of terminal patients. ${ }^{36}$

We proposed a preliminary benchmark process based on qualitative evaluation. This process has been designed and organized by the Social Health Directorate (Pla Director

Table 2. Key Processes in Benchmarking Palliative Care Services and Networks in Catalonia

Selection of Nuclear Expert Group (NEG) or Steering Committee

Selection of comparable services, settings and/or demographic scenarios

Selection of dimensions to be analyzed

Review evidence and experience and define models-of-excellence adapted to specific settings and demographic scenarios

Indicators and parameters of excellence

Describe and measure the models

Compare

Identify strong points, weaknesses and gaps

Based on gaps and weaknesses identified, propose measures for improvement and indicators to monitor Implement measures and evaluate results 
Sociosanitari) at the DoH and the WHO Collaborating Center for Palliative Care Public Health Programs at the Catalan Institute of Oncology. The study was financed, at least in part, by the Agency for Quality of the Spanish Ministry of Health as one of the activities within the National Strategic Plan for Palliative Care.

\section{Aims}

The aim of the current work is to describe the initial implementation, and preliminary results, of a benchmark process designed to evaluate some of the dimensions of organization of palliative care services and to compare those to similar demographic scenarios or settings with a view to promoting interaction and to reducing variability between districts and settings. The focus has been on promoting improvement in quality in our region by identifying good practices as well as areas for improvement of services. Furthermore, we formulated recommendations to the Catalan DoH for the improvement of services based on 20 years experience of an initial WHO Demonstration Project.

\section{Methodology}

The methodology for the benchmark process is described in Table 2. A core or Steering Committee or Nuclear Expert Group (NEG) of 20 health care professionals was proposed by the DoH and the WHOCC. The main criterion was that of multidisciplinary composition. Hence, those included in the NEG were health care professionals in palliative care services, primary care services, and stakeholders (policymakers, funders, district health authorities, leaders of other health care services, managers of health care organizations, and providers), and representatives of regional and district health authorities based in four types of territories: rural, semiurban, urban, and metropolitan. The NEG took responsibility for reviewing all available information, to propose the methodology, to develop the criteria, to select the dimensions to be described, and to compare the data with our previous qualitative analyses. ${ }^{19}$ The proposed structure of the benchmark meeting consisted of an introductory lecture and a lecture on methodological aspects of the benchmark process. These were followed by eight workshops representing the four types of territories. Each workshop had a chairperson, plus one person to review the evidence and two persons describing their clinical/administrative experiences to the audience composed of the conference attendees. The selected dimensions were listed for structured discussion. There were three levels for consensus scoring (no consensus, mid-level, and high level) and the recommendations were reviewed internally to ensure that high consensus level was achieved, and only these recommendations were included in the document submitted to the DoH.

The proceedings of all meetings of the NEG and all workshops of subsequent benchmark meetings were recorded and disseminated among interested parties.

Comparisons and discussions of different experiences and prioritization of options in workshop sessions based on the three consensus levels were made and then formally presented in plenary sessions. Finally, consensus recommendations that achieved high consensus level were collated for submission to the $\mathrm{DoH}$.
Table 3. Selected Dimensions for Benchmark

Organization of specialist palliative care services in the sector and in specific settings

Organization of continuous- and emergency-care

Access, criteria, time, and length of intervention of palliative care services

Care of noncancer terminally ill patients

Palliative care in primary care services

Palliative care in emergency services

Palliative care training for health care professionals in districts

\section{Results}

\section{Steering committee or NEG}

Table 3 summarizes, based on previous experience, the 8 dimensions identified as areas requiring urgent need for improvement. ${ }^{37}$ The 37 Catalan Health Care Sectors were listed, and matched according to their demographic/geographic characteristics into 4 main demographic scenarios. Table 4 summarizes the conventional and specialist palliative care services in different types of sectors providing health care services in Catalonia. ${ }^{38}$

The settings of palliative care services and the organizational patterns are described in Figure 1. Definitions of services were derived from the definitions contained in CCOMS, (WHO Collaborating Center for Palliative Care Public Health Programs) ${ }^{7}$ and DirCAT (Catalan Directory of Palliative Care Services). ${ }^{17}$

The NEG proposed certain criteria by which 3-4 attendees of each sector would be invited to participate in benchmark meetings. The selection was broad-based to be multidisciplinary and included representatives from specialist palliative care services, primary care teams, stakeholders, managers in palliative care provision and primary care as well as administrators from the various regional and/or district health authorities.

The individuals selected to participate were required, prior to attending the meeting, to evaluate the status of the various dimensions (described above) in their districts. Quantitative and qualitative data were to be collected (number of services, number of processes of specialist services, etc.) and were analyzed using the "Strong and Weak Opportunities and Threats" (SWOT) analysis. ${ }^{37}$ Strong points were listed to identify areas of good practice and benchmark while weak points were identified as areas for improvement, with aims and actions being proposed.

Benchmark meeting. The proposed methodology of the benchmark meeting consisted of a plenary session with two lectures dealing with methodology. The rest of the day consisted of workshops in which these aspects were amplified and debated (Fig. 2).

The four morning workshops brought together the health care professionals and stakeholders, including planners and health authorities dealing with the four different scenarios or sectors (acute care hospitals, social health centers, nursing homes, primary care centers), to describe the current organization of palliative care services and, as well, the organization 
Table 4. Conventional and Specialist Palliative Care Services in Different Types of Sectors of Catalonia

\begin{tabular}{|c|c|c|c|c|}
\hline Type & Characteristics & Number & $\begin{array}{l}\text { Conventional } \\
\text { (nonpalliative care) } \\
\text { resources }\end{array}$ & $\begin{array}{c}\text { Palliative } \\
\text { care resources }^{\text {a }}\end{array}$ \\
\hline Rural & $<50,000$ citizens & 9 & PCC & $\begin{array}{l}1 \text { support team available } \\
\text { in all settings (home, hospital, } \\
\text { others) }\end{array}$ \\
\hline Rural-urban & 50-150,000 citizens & 18 & $\begin{array}{l}\text { CH } \\
\text { PCC } \\
\text { DGH }\end{array}$ & $\begin{array}{l}\text { Unit in the SHC or DGH, } \\
\text { HCST, HST, OPC }\end{array}$ \\
\hline & $\begin{array}{l}\text { Intermediate: rural areas } \\
\text { with } 1-3 \text { small cities }\end{array}$ & & PSHC & \\
\hline $\begin{array}{l}\text { Urban (Girona, Lleida, } \\
\text { Tarragona) }\end{array}$ & $\begin{array}{l}200-300,000 \text { citizens } \\
1 \text { provincial capital }\end{array}$ & 3 & $\begin{array}{c}\text { PCC } \\
\text { CH } \\
1 \mathrm{TH} \\
1 \mathrm{DGH} \\
\text { PSHC }\end{array}$ & $\begin{array}{l}\text { Unit in Hospitals and } \\
\text { SHC }+2 \text { HST }+3 \text { HCST }\end{array}$ \\
\hline $\begin{array}{l}\text { Metropolitan (Barcelona, } \\
\text { Badalona, Hospitalet, } \\
\text { Sabadell-Terrassa) }\end{array}$ & $400-600,000$ citizens & 7 & $\begin{array}{l}\text { PCC } \\
1 \mathrm{TH} \\
\mathrm{DGH}\end{array}$ & $\begin{array}{l}5 \text { levels of complexity of PCS: } \\
\text { Reference unit + HST + OPC + HST } \\
\text { in DGH + HCST / 100,000 } \\
\text { citizens or district }\end{array}$ \\
\hline Total & $\begin{array}{l}\text { Metropolitan Barcelona } \\
7,300,000 \text { citizens }\end{array}$ & 37 & $\begin{array}{l}\text { PSHC } \\
\text { Hospitals } \\
\text { PSHC } \\
\text { PCT }\end{array}$ & $\begin{array}{l}\text { HCST / 100,000 citizens } \\
\text { HST in every Hospital Units } \\
3 \text { levels, OPC }\end{array}$ \\
\hline
\end{tabular}

${ }^{\mathrm{a}}$ As agreed in the benchmark meeting.

PCC, primary care center; $\mathrm{CH}$, community hospital; DGH, district general hospital; $\mathrm{TH}$, teaching hospital; OPC, outpatient clinic; PSHC, polyvalent social health center; PCT, primary care teams; HST, hospital support teams; HCST, home care support teams; SHC, social health centers; PCS, palliative care services.

for continuous care, coordination, and emergency care. The four afternoon workshops had a mixed composition of topics for discussion selected from the four scenarios. These topics included care for noncancer terminally ill patients, palliative care in emergency services, palliative care in primary care services, and training in palliative care at the district level.

Representatives of the scientific societies were also invited to attend the conference. These included the Catalan Society

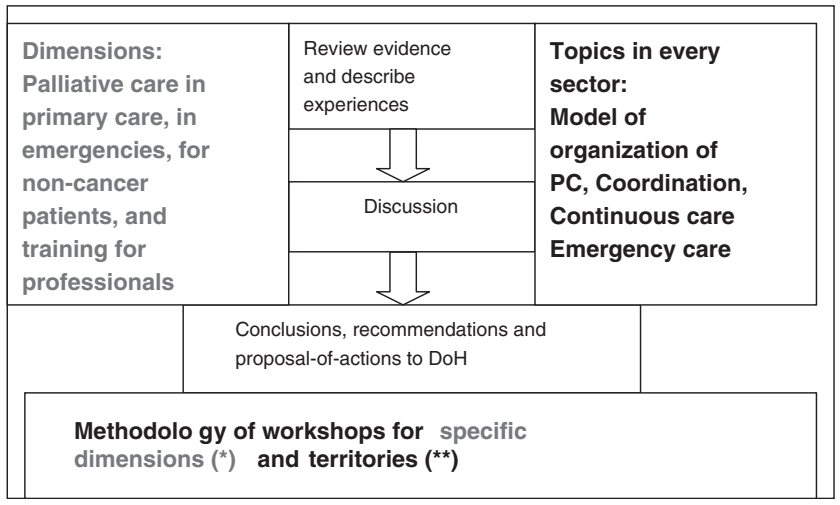

FIG. 2. Flow chart of structure and methodology for workshops in the benchmark meeting. ${ }^{*}$ Dimensions to be described and compared. ${ }^{* *}$ Territory: demographic settings or sectors (rural, rural-urban, urban, metropolitan) to compare model of organization of palliative care, coordination, continuous care, emergency care. of Palliative Care, Catalan Society for Primary Care, and Catalan Society for Emergency Medicine. The meeting took place on May 8, 2008 in Barcelona.

Participants. A total number of 154 health care professionals and stakeholders were invited to attend and, of these, 114 took part in the conference. Their distributions by expertise and specializations are summarized in Table 5. All participants were asked to prepare their own positions on each of the dimensions so that the meeting could be more proactive.

General recommendations to the DoH. The main recommendations are listed in Tables 6 and 7. The ones achieving the highest level of consensus were: the need to implement acute palliative care units in acute bed university hospitals; the need for systems of continuous care and emergency care for every district; accessibility to specialist services in every setting; better implementation of resources and measures for the care of noncancer terminally ill patients; the need to improve the training of personnel and to adapt the organization of primary care services to the needs of the patients and their families (Table 8). Another key consensus recommendation was to propose that every district, or sector, develops and implements specific plans for end-of-life care.

\section{Short-term results}

The recommendations following from the consensus agreements have been the bases of the document "Model for End-of-Life Care and Palliative Care in Catalonia"39 (El Model d'Atenció al Final de la Vida i de Cures Pal.liatives de Catalunya), 
Table 5. Composition, Geographical Provenance, and Health Care Function of the Participants/ Attendees at the Benchmark Meeting

Invited: 154

Attendees: 114

By geographical provenance:

Rural: 25 (22\%)

Urban-rural: 29 (25\%)

Urban: $27(23 \%)$

Metropolitan: 33 (30\%)

By profession:

Doctors: $66(58 \%)$

Nurses: $31(27 \%)$

Other: $21(15 \%)$

By function ${ }^{\mathrm{a}}$ :

Professional health-care provider: $81(71 \%)$

Policy, managerial, administration: 33 (29\%)

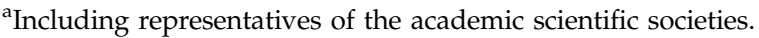

which describes the model for care and organization and that proposes areas for improvement and innovation in our palliative care system. Over the next 5 years, this document will be the main reference for the planning and implementation of measures by the DoH, the district health authorities, and the various health care providers. Currently, there are formal expert groups developing specific recommendations for specific topics, including complexity. ${ }^{40}$

To implement systematic continuing training for primary care professionals, basic workshop, basic course, and an intermediate-level online course have been designed. There is a formal plan to implement the basic workshop for up to $50 \%$ of primary care doctors and nurses within 2 years. A further objective is to achieve greater than $50 \%$ coverage for the basic course and the intermediate-level online course in primary care within 5 years. The Catalan Health Service has prioritized training in palliative care, together with the identification of advanced terminal patients and the design of policies for

Table 6. Weak Points and Recommendations for Some Dimensions

\begin{tabular}{ll}
\hline Workshop (dimensions) & Weak points ide \\
\hline Sector Planning & Variability \\
& \\
$\begin{array}{ll}\text { Access/Early intervention/Continuous/ } \\
\text { Emergency care }\end{array}$ & $\begin{array}{c}\text { Lack of policies } \\
\text { and systems }\end{array}$
\end{tabular}

Noncancer terminal patients' care Low coverage

Organization in University Hospitals

PC in Primary Care Services Organization

PC in Emergency services Organization

Education and Training

$\begin{gathered}\text { Variability Lack } \\ \text { of resources }\end{gathered}$
Variability

Lack of training and specific knowledge

Variability, low coverage
1. Sectors must design and implement end-of-life comprehensive plans

2. Implement a specific district system for continuing/emergency care and training

1. Establish formal agreements of coordination conventional-specialist services, with criteria complexity and intervention

2. Nurses be able to indicate palliative care services

3. Establish advance care planning and case management as care methodologies

4. Select and establish a system of continuous care and emergency care

1. HCST increase the proportion of NCTP to $>50 \%$

2. Specialist nurses in hospitals for NCTP

3. Agreement HST-geriatric teams to provide shared care

4. Establish guidelines to screen, identify and clinical care NCTP

1. University hospitals must have $\mathrm{PC}$ systems including PCU, OPC, HST, and DC, and education \& research structures

1. Change organization of PCS: nurse specialists, accessibility, increase of home care

2. High coverage training in PC for all health-care professionals

1. Emergency care professionals training PC

2. Physical structure and privacy allowing last-days care

3. Joint policies

4. Access to clinical information of patients and advance directives

1. Training plans for every district: aims, targets, levels, coverage, and methods

2. High coverage for training of primary care doctors and nurses

3. Training methodology for palliative care services

4. Education and advocacy for the public

HST, hospital support teams; HCST, home care support teams; NCTP, Noncancer terminally ill patients; PCU, palliative care units; OPC, outpatient clinics; DC, day care. 
Table 7. Common and Specific Recommendations for Demographic Scenarios

Workshop

(demographic settings)

$\begin{array}{ll}\begin{array}{l}\text { Common recommendations } \\ \text { (see also by dimensions) }\end{array} & \begin{array}{c}\text { Every sector needs to have an end-of-life plan, including measures in general services, } \\ \text { specialist services, a formal system for continuing care and emergencies, and formal } \\ \text { training program to all levels }\end{array} \\ \text { All levels of palliative care complexity Palliative care in university hospitals including PCU, } \\ \text { OPC, HST, and research \& training units } \\ \text { Specialist nurses for noncancer patients in hospitals }\end{array}$

HST, hospital support teams; HCST, home care support teams; NCTP, noncancer terminally ill patient; PCU, palliative care unit; OPC, outpatient clinic; DC, day care.

end-of-life care as key issues in all managerial contracts signed with primary care teams. Districts are required by the DoH to implement systems and policies for continuous care and emergency care for advanced terminally ill patients by 2009-2010.

The methodology for district planning is currently being tested in one of the regions (the Pyrenees) of Catalonia. An end-of-life plan is being developed that includes all of the recommended elements described above, and the plan will be extended to other regions in the short- to medium-term future.

\section{Discussion}

\section{Methodology}

The benchmark methodology has been used previously in the health care sector to assess and to compare specific aspects of health care and organization in different settings. Also, different scenarios within similar organizations have been compared with the aim of identifying areas for improvement and in which systems could be designed to help achieve these objectives.

Our selection of dimensions for assessment was based on a previous qualitative analysis ${ }^{24}$ that identified the strong points for wider application, as well as the main areas requiring improvement. The analyses were focused on organizational aspects and the findings were reviewed and prioritized by the current Steering Committee.

The selection of demographic scenarios was based on the previous experience of constructing a map of health care resources in Catalonia, ${ }^{40}$ which identified similar patterns of organizations of health care, and that could also be applied to palliative care dimensions and organizations.

The combination of an expert group and benchmark meetings of participants who would be intimately involved in implementation of any such improvement plans has been explored successfully in previous experiences addressing various aspects of health care provision. ${ }^{37}$

Attendance at the benchmark meeting. The composition and status of those attending the benchmark meeting were representative of those specifically involved in palliative care in our region, and included the different health care providers and stakeholders involved in the sector. All districts, care settings, health care professionals, and stakeholders were represented.

Constructing recommendations. The recommendations were developed following a systematic process of reviewing evidence, discussing the different experiences, and prioritizing the recommendations according to the level of consensus achieved. Only recommendations achieving the high level of consensus were selected for inclusion into the document submitted to the DoH.

The usefulness of the benchmark process could be described as bidirectional.

\section{Short-term results}

The most relevant immediate-term outcome has been the document entitled "The Model of End-of-Life and Palliative

Table 8. Recommendations for Improving Palliative Care in Primary Care Settings

Training in palliative care, communication, and ethical issues

Improve accessibility for patients and families, continuing care, and home care intensity with a preventive and advance care planning approach

Identify (Gold Standards Framework), register, and improve care for noncancer terminally ill patients

Develop and evaluate experiences of nurse specialist and medical reference for palliative care in primary care teams

Improve teamwork between doctors, nurses and other professionals

Start bereavement programs

Link with specialist palliative care services 
Care in Catalonia." This document will be the basis for the planning and development of palliative care in our region over the next few years. It will involve the $\mathrm{DoH}$, the various district health authorities, and health care providers. The current estimate is that approximately $50 \%$ of the specific recommendations are being implemented, and a 5-year action plan is currently being defined.

The benchmark process and meeting of interested parties has added consensus, agreement, and specific evidence to the process of evaluation and implementation of the innovations needed in the palliative care program at the $\mathrm{DoH}$. The process takes into account 20 years of experience of a WHO Demonstration Project as well as the needs of all stakeholders including policymakers, funders, district health authorities, managers, and health care professionals working in palliative, primary, and emergency care.

\section{Limitations}

This article describes the preliminary phase of a benchmark process that was initiated with the objective of reducing variability and improving the quality of palliative care services in district networks in Catalonia. The initial outcomes of the benchmark process are associated with aspects that are difficult to quantify. Nevertheless, the influence of the benchmark process has, presumably, been high because the recommendations have been discussed and agreed-upon by the main protagonists in the field of palliative care provision in the region.

\section{Further actions}

The implementation of measures for improvement is a complex process since there many individuals and agencies involved including planners, funders, care providers, and health care professionals in every district. To reinforce the concepts, we plan to establish annual monitoring follow-ups involving in the steering committee at the Department of Health and, at a later stage, repeat the benchmark process.

\section{Acknowledgments}

Editorial assistance was provided by Dr. Peter R. Turner of t-SciMed (Reus, Spain).

\section{Author Disclosure Statement}

No competing financial interests exist.

\section{References}

1. Gómez-Batiste X, Porta-Sales J, Pascual A, Nabal M, Espinosa J, Paz S, Minguell C, Rodríguez D, Esperalba J, Stjernsward J, Geli M: Catalonia WHO Palliative Care Demonstration Project at 15 Years (2005). J Pain Symptom Manage 2007;33:584-590.

2. Gómez-Batiste X, Porta-Sales J, Tuca-Rodriguez A, PérezMarin FJ, Pascual-Lopez A, Espinosa-Rojas J, MañasIzquierdo V: Symptom control efectiveness in advanced cancer patients cared by Spanish palliative care teams: A nation-wide study [abstract]. 5th EAPC Research Forum. Trondheim: May 2008; 350.

3. Gómez-Batiste X, Tuca A, Corrales E, Porta-Sales J, Amor M, Espinosa J, Borras JM, De La Mata I: Resource consumption and costs of palliative care services in Spain: A multi-center prospective study. J Pain Symptom Manage 2006;31:522532.

4. Serra-Prat M, Gallo P, Picaza JM: Home palliative care as a cost-saving alternative: Evidence from Catalonia. Palliat Med 2001;15:271-278.

5. Gómez-Batiste X, Porta-Sales J, Paz S, Stjernsward J: Palliative medicine. Models of organization. In: Walsh D (ed): Palliative Medicine. Philadelphia: Elsevier, 2008, pp. 23-29.

6. Ferris FD, Balfour HM, Bowen K, Farley J, Hardwick M, Lamontagne C, Lundy M, Syme A, West PJ: A model to guide patient and family care: Based on nationally accepted principles and norms of practice. J Pain Symptom Manage 2002;24:106-123.

7. Gómez-Batiste X, Paz S, Porta-Sales J, Espinosa J, Trelis J, Esperalba J: Basic definitions, principles, and concepts on the organization of public health palliative care programmes and services. www.iconcologia.net/catala/qualy/centre descripcio.htm (Last accessed August 24, 2010).

8. Porta-Sales J, Gomez-Batiste X, Pascual-Lopez A: Acute palliative medicine units. In: Walsh D (ed): Palliative Medicine. Philadelphia: Elsevier, 2008, pp. 208-212.

9. Walsh D: The business of palliative medicine. Part IV: Potential impact of palliative medicine acute care inpatient unit in a tertiary care cancer center. Am J Hosp Palliat Care 2004;21:217-221.

10. Bruera E, Sweeney C: The development of palliative care at the University of Texas MD Anderson Cancer Center. Support Care Cancer 2001;9:330-334.

11. Mercadante S, Villari P, Ferrera P: A model of acute symptom control unit: Pain relief and palliative care unit of La Maddalena. Support Care Cancer 2003;11:114-119.

12. Gómez-Batiste X, Porta J, Tuca A: Palliative care service at the Institut Català d'Oncologia, Barcelona. Eur J Palliat Care 2003;10:2002-2005.

13. Gómez-Batiste $X$ : Modelos de organización en cuidados paliativos. In: Gómez-Batiste X, Porta J, Tuca A, Stjernsward J (eds): Organización de servicios y programas de Cuidados Paliativos. ARAN, Madrid: ARAN, 2005, pp. 55-80.

14. Franks PJ, Salisbury C, Bosanquet N, Wilkinson EK, Kite S, Naysmith A, Higginson IJ: The level of need for palliative care: A systematic review of the literature. Palliat Med 2000;14:93-104.

15. García-Pérez L, Linertová R, Martín-Olivera R, SerranoAguilar P, Benítez Rosario MA: A systematic review of specialised palliative care for terminal patients: which model is better? Palliat Med 2009;23:17-22.

16. Els serveis per a la salut mirant cap al futur. Mapa sanitari, sociosanitari i de salut pública de Catalunya. Departament de Salut, Generalitat de Catalunya, 2006.

17. CatSalut. Memoria 2008. Departament de Salut. Generalitat de Catalunya.

18. Paz-Ruiz S, Gomez-Batiste X, Espinosa J, Porta-Sales J, Esperalba J: The costs and savings of a regional public palliative care program: The Catalan experience at 18 years. J Pain Symptom Manage 2009;38:87-96.

19. Directory of Palliative Care Services in Catalonia. The "Qualy" Observatory on End of Life. 2009. www.iconcologia.net (Last accessed August 24, 2010).

20. Brugulat $\mathrm{P}$, de la Puente ML, Masachs E, Mompart A: La millora de l'atenció al final de la vida: la perspectiva dels familiars de pacients i dels professionals de la salut. Barcelona: Planificació i avaluació; 25. Generalitat de Catalunya, Departament de Salut; 2008. 
21. Gómez-Batiste $X$, Nabal Vicuña $M$, Trelis Navarro J, Roca Casas J, Porta-Sales J, Paz Ruiz S, Espinosa Rojas J: Evaluación cualitativa del desarrollo del proyecto Demostrativo OMS de Cuidados Paliativos de Cataluña a los 15 años de su implementación y propuestas de mejora. Med Pal (Madrid) 2008;15:293-300.

22. Camp R: Benchmarking: The Search for Industries Best Practices that Leads to Superior Performance. Milwaukee, WI: ASQC Quality Press, 1989.

23. Pasman HR, Brandt HE, Deliens L, Francke AL: Quality indicators for palliative care: A systematic review. J Pain Symptom Manage 2009;38:145-156.

24. Wait S, Nolte S: Benchmarking health systems: Trends, conceptual issues and future perspectives. Benchmark Int J 2005;12:436-448.

25. Kay JFL: Health care benchmarking. Med Bull 2007;2: 22-27.

26. Kiefe CI, Weissman NW, Allison JJ, Farmer R, Weaver M, Williams D: Identifying achievable benchmarks of care: concepts and methodology. Int J Qual Health C 1998;10:443447.

27. Davies S, Cripacc CG: Supporting quality improvement in care homes for older people: The contribution of primary care nurses. J Nurs Manag 2008;16:115-120.

28. Cohen LM, Germain MJ: Measuring quality of dying in endstage renal disease. Semin Dial 2004;17:376-369.

29. Richards MA, Parrot JC: Tertiary cancer services in Britain: Benchmarking study of activity and facilities at 12 specialist centres. BMJ 1996;313:347-349.

30. Bowman C, Johnson M, Venables D, Foote C, Kane RL: Geriatric care in the United Kingdom: aligning services to needs. BMJ 1999;319:1119-1122.

31. Greenberg A, Angus H, Sullivan T, Brown AD: Development of a set of strategy-based system-level cancer care performance indicators in Ontario, Canada. Int J Qual Health C 2005;17:107-114.

32. Tawfik-Shukor AR, Klazinga NS, Arah OA: Comparing health system performance assessment and management approaches in the Netherlands and Ontario, Canada. BMC Health Serv Res 2007;7:25-33.

33. Grunfeld E, Lethbridge L, Dewar R, Lawson B, Paszat L, Johnston G, Burge F, McIntyre P, Earle CC: Towards using administrative databases to measure population-based in- dicators of quality of end-of-life care: Testing the methodology. Palliat Med 2006;20:769-777.

34. Murray JA, Murray MH: Benchmarking: A tool for excellence in palliative care. J Palliat Care 1992;8:41-45.

35. Weissman DE, Meier DE: Operational features for hospital palliative care programs: consensus recommendations. J Palliat Med 2008;11:1189-1194.

36. Fowell A, Finlay I, Johnstone R, Minto L: An integrated care pathway for the last two days of life: Wales-wide benchmarking in palliative care. Int J Palliat Nurs 2002;8:566-567.

37. Ellershaw J, Gambles M, McGlinchey T: Benchmarking: a useful tool for informing and improving care of the dying? Support Care Cancer 2008;16:813-819.

38. Twadle ML, Maxwell TL, Cassel JB, Liao S, Coyne PJ, Usher BM, Amin A, Cunny J: Palliative care benchmarks from academic centers. J Palliat Med 2007;10:86-98.

39. Gómez-Batiste X, Ferris F, Paz S, Espinosa J, Stjernsward J, Esperalba J: Ensure quality public health programmes. A Spanish Model. Eur J Palliat Care 2008;15:195-199.

40. Els serveis per a la salut mirant cap al futur. Mapa sanitari, sociosanitari i de salut pública de Catalunya. Departament de Salut, Generalitat de Catalunya, 2006.

41. El Model d'Atenció al Final de la Vida i de Cures Pal.liatives de Catalunya. Pla Director Sociosanitari. Departament de Salut. Generalitat de Catalunya. (in press).

42. Esteban M, Aranzana A, Besora MI, Bullich I, Busquet X, Castells G: Grup de treball de complexitat. Descripció i consens dels criteris de complexitat asistencial i nivells d'intervenció en l'atenció al final de la vida. Societat Catalanobalear de cures pal.liatives, Pla Director sociosanitari, Departament de Salut, 2009.

Address correspondence to: Xavier Gómez-Batiste, M.D., Ph.D. Catalan Institute of Oncology WHO Collaborating Center for Palliative Care Public Health Programs Av. Gran Via 199

08907 L'Hospitalet (Barcelona) Spain

E-mail: Xgomez.WHOCC@iconcologia.net 